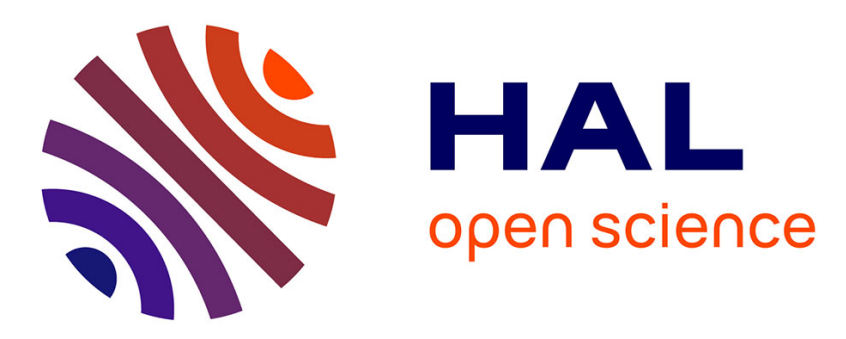

\title{
Optimization of the synthesis of polyhydroxyurethanes using dynamic rheometry
}

Sofia Benyahya, Bernard Boutevin, Sylvain Caillol, Vincent Lapinte, Jean-Pierre Habas

\section{- To cite this version:}

Sofia Benyahya, Bernard Boutevin, Sylvain Caillol, Vincent Lapinte, Jean-Pierre Habas. Optimization of the synthesis of polyhydroxyurethanes using dynamic rheometry. Polymer international, 2012, 61, pp.918-925. 10.1002/pi.4159 . hal-00708510

\section{HAL Id: hal-00708510 https://hal.science/hal-00708510}

Submitted on 15 Jun 2012

HAL is a multi-disciplinary open access archive for the deposit and dissemination of scientific research documents, whether they are published or not. The documents may come from teaching and research institutions in France or abroad, or from public or private research centers.
L'archive ouverte pluridisciplinaire HAL, est destinée au dépôt et à la diffusion de documents scientifiques de niveau recherche, publiés ou non, émanant des établissements d'enseignement et de recherche français ou étrangers, des laboratoires publics ou privés. 


\section{Optimization of the synthesis of poly(hydroxyurethane)s using dynamic rheometry.}

\begin{tabular}{|r|l|}
\hline Journal: & Polymer International \\
\hline Manuscript ID: & PI-11-0472.R1 \\
\hline Diley - Manuscript type: & Original Article \\
\hline Complete List of Authors: & $\begin{array}{l}\text { benyahya, sofia; ICGM, IAM } \\
\text { bernard, Boutevin; ICGM, IAM } \\
\text { caillol, sylvain; ICGM, IAM } \\
\text { Lapinte, Vincent; Université Montpellier II, Institut Charles Gerhardt } \\
\text { Montpellier UMR5253 CNRS-UM2 - Equipe Ingénierie et Architectures } \\
\text { Macromoléculaires } \\
\text { habas, jean-pierre; ICGM, IAM }\end{array}$ \\
\hline Key Words: & $\begin{array}{l}\text { poly(hydroxyurethane), rheology, glass transition temperature, renewable } \\
\text { resources, entanglement, molecular weight }\end{array}$ \\
\hline \multicolumn{2}{|c}{} \\
\hline
\end{tabular}

SCHOLARONE

Manuscripts 


\title{
poly(hydroxyurethane)s using dynamic rheometry.
}

\author{
Sofia Benyahya, Bernard Boutevin, Sylvain Caillol, Vincent Lapinte, Jean-Pierre Habas* \\ Institut Charles Gerhardt Montpellier UMR5253 CNRS-UM2-ENSCM-UM1, Equipe Ingénierie \\ et Architectures Macromoléculaires, Université Montpellier II, Place Eugène Bataillon, cc 17-02. \\ 34095 Montpellier Cedex 5 (France). \\ sofia.benyahya@enscm.fr,_ bernard.boutevin@enscm.fr,_ sylvain.caillol@enscm.fr, \\ vincent.lapinte@univ-montp2.fr, jean-pierre.habas@univ-montp2.fr \\ *: Corresponding Author:
}

Mail : jean-pierre.habas@univ-montp2.fr.

Tel: 33-4-67-14-37-80; Fax: 33-4-67-14-72-20

http://mc.manuscriptcentral.com/pi-wiley 


\begin{abstract}
Poly(hydroxyurethane)s produced by the reaction between dicyclocarbonate and diamine groups are often presented as possible candidates to substitute classical poly(urethane)s based on isocyanate precursors. In the literature, the synthesis of this class of polymers is often performed according to arbitrary conditions of time and temperature without any scientific justification. Then, the real potential of poly(hydroxyurethane)s is probably badly known. Numerous contradictions in previous published results seem to support this hypothesis. Our paper proposes two methodologies based on dynamic rheometry to determine the optimized conditions for the synthesis of PHUs. The case of a polyhydroxyurethane formed by the reaction between 1,10 diaminodecane and a dicyclocarbonate bearing a central aromatic group is described more precisely. The first approach consists in conducting different rheological experiments (kinetics, thermomechanical analyses) in-situ on the reactive mixture. The second one retains the same technique to qualify the viscoelastic properties of poly(hydroxyurethane)s synthesized according to different conditions. In this latter case, all samples present a thermomechanical behavior of amorphous thermoplastic polymer. But discrepancies are observed with regard to the value of the $\mathrm{Tg}$ and the existence or not of a rubbery zone. The confrontation of these data with SEC results shows that these differences are direct consequences of the polymer molecular weight that can be predicted using macromolecules theory. The properties of the poly(hydroxyurethane)s obtained after optimization of the polymerization reaction were compared with literature data in order to complete the evaluation of the efficiency of the rheological methodology.
\end{abstract}

Keywords: poly(hydroxyurethane), rheology, glass transition temperature, renewable resources, molecular weight. 


\section{1 - Introduction}

Polyurethanes are very interesting polymeric materials that allow a huge variety of industrial applications from paints, adhesives and binders to materials for aeronautic industry (propellants). They are synthesized from diol and diisocyanate reactants that produce a carbamate (urethane) bond. According to the nature and length of diol chains, a large range of polyurethanes can be developed with specific physico-chemical properties. This versatility explains the spreading of polyurethanes over the world. Polyurethanes remain at the $6^{\text {th }}$ position (tons) of most used polymers in the world. The major problem of polyurethanes is related to the toxicity of diisocyanate precursors. ${ }^{[1]}$ A non-hazardous for human and environment-isocyanate-free route to generate carbamate groups is based on a reaction between a cyclocarbonate and an amine. ${ }^{[2-4]}$ Various methods of preparation of cyclocarbonates have already been described. ${ }^{[5]} \mathrm{A}$ first chemical route is based on the use of carbon dioxide with either epoxy resins or 1,2-diols. ${ }^{[6-9]} \mathrm{A}$ second approach consists in preparing five-membered ring cyclocarbonates from phosgene and 1,2-diols. ${ }^{[10-12]}$ A third method lies in a trans-carbonatation reaction by an exchange between organic carbonate and hydroxyl compound. ${ }^{[13]}$ An alternative route consisting in the reaction between urea and 1,2- or 1,3-diols is another carbonatation method. ${ }^{[14-15]}$ Finally, a last methodology uses the direct esterification of glycerin cyclocarbonate with carboxylic acid or acyl chloride to yield corresponding ester bearing cyclocarbonate. Reaction with acyl chloride is rapid and quantitative, whereas carboxylic acid lead to slow and reversible reactions (transesterification). ${ }^{[16]}$

As mentioned hereabove, cyclocarbonates are valuable for the synthesis of isocyanate-free poly(urethane)s also designed as poly(hydroxyurethane)s or PHUs. This class of polymers arises a great interest in the academic and industrial communities. ${ }^{[17-19]}$ Endo et al. undertook an 
important fundamental work with the synthesis and description of different kinds of linear poly(hydroxyurethane)s. ${ }^{[10-12,20-22]}$ The approach based on cyclic dicarbonates and diamines was also retained by Burgel and Fedtke to prepare other thermoplastic PHUs. ${ }^{[23]}$ In fact, a large range of poly(hydroxyurethane)s could be prepared and their characteristics were interpreted as being influenced by the nature of the diamine and cyclocarbonate comonomers. ${ }^{[4,16,21,24,25]}$ For instance, Ubaghs prepared PHU series from the reaction of phenoxycarbonyloxymethyl ethylene carbonate with five linear aliphatic diamines $\mathrm{H}_{2} \mathrm{~N}-\left(\mathrm{CH}_{2}\right)_{\mathrm{n}}-\mathrm{NH}_{2}, \mathrm{n}$ ranging from 2 (i.e. 1,2-diaminoethane) to 6 (i.e. 1,6-diaminohexane). ${ }^{[16]}$ Its research showed in particular that the glass transition temperature $(\mathrm{Tg})$ of the PHU decreased with increasing number of methylene groups in the diamine structure, i.e. with growing flexibility of the chain between the hydroxyurethane groups (Table 1).

\section{Insert Table 1.}

Steblyanko conducted an analogous investigation with thermoplastic PHUs produced by the reaction between an aromatic dicyclocarbonate and various diamines. ${ }^{[4]}$ But, in this latter case, the author did not observe a continuous decrease of the polymer $\mathrm{Tg}$ with the size of the diamine chain (Table 2). The highest value was obtained with the material based on a sequence of three methylene units. The reported evolution could remind the even-odd effect due to the number of methylene units and that was already described with some polyamides ${ }^{[26-28]}$ and polyurethane ureas. ${ }^{[29]}$ But, in these particular cases, the critical temperatures of the polymer ( $\mathrm{Tg}$ and/or melting point) are always lower when there is an odd number of methylene groups in the diamine. Indeed, for an even number of methylene units the packing of the crystals is operated in planar zig-zag conformation while an odd number of $\mathrm{CH}_{2}$ groups does not allow the same regular 
packing. It is important to note that in ref [4], the evolution of the Tg is purely contrary. So, the even-odd effect seems not to be relevant for PHUs.

\title{
Insert Table 2.
}

\begin{abstract}
A new apparent contradiction as regards PHUs properties could be reported by the comparison of two researches dealing with the properties of a same poly(hydroxyurethane) formed by the stepgrowth polyaddition of another aromatic dicyclocarbonate with hexamethylene diamine. In the first study ${ }^{[21]}$, the $\mathrm{Tg}$ of the polymer was measured close to $34^{\circ} \mathrm{C}$ while it was about $47^{\circ} \mathrm{C}$ in the second one. ${ }^{[25]}$
\end{abstract}

These important discrepancies seem to show that the conditions used for the synthesis of these PHUs were not optimal. In each case, the conditions of time and temperature were fixed without any form of justification. To our knowledge, no work examined the influence of these synthesis parameters on the final characteristics of PHUs. In other words, PHUs properties described up to now do not probably reflect the real potential of this class of polymers. Given this situation, we wished to report here an efficient methodology, based on the use of rheometry, to synthetize PHUs under optimal conditions. To illustrate our approach, a new poly(hydroxyurethane) was prepared by reaction between an aromatic dicyclocarbonate named terephthaloyl dicyclocarbonate (DCter) and an aliphatic diamine, 1,10-diaminodecane (DA10) (Scheme 1). As rheological measurements can usually be carried out on polymers of very different nature ranging from the solid to the liquid state, we proposed two routes to evaluate the best temperature and time conditions that lead to a DCter-DA10 PHU with optimal properties. The first method consisted in conducting thermomechanical experiments directly on the reactive mixture to determine the temperature range where the polymerization occurred. In addition, rheological 
kinetics were conducted to define the time to complete the reaction at several fixed temperatures. The second method was based on the description and understanding of the thermomechanical behavior of samples made of the same poly(hydroxyurethane) but prepared according to variable synthesis conditions. The glass transition temperature and the molecular weight between entanglements were chosen as evaluation criteria. The consecutive confrontation of these results was undertaken with the information obtained by SEC and DSC techniques to examine the real merits of the rheological methodology.

\section{Insert Scheme 1}

\section{2 - Experimental Section}

\section{1 - Materials}

The aromatic dicyclocarbonate named terephthaloyl dicyclocarbonate (DCter) was prepared by esterification of terephthalic acid using glycerin cyclocarbonate according to a methodology already reported. ${ }^{[30]}$ 1,10-Diaminodecane (DA10) was purchased from Aldrich (Aldrich, France). Dimethylformamide (DMF) from SDS Carlo Erba (Val de Reuil, France) was dried according to current methods, distilled and stored under argon atmosphere before final use. DMSO- $d_{6}$ was purchased from Eurisotop (Saint-Aubin, France).

\section{2 - Physicochemical characterization}

\subsection{1 - Analytical techniques}

${ }^{1} \mathrm{H}$ and ${ }^{13} \mathrm{C}$ spectra were recorded on a Bruker DRX $400 \mathrm{MHz}$ spectrometer operating at a frequency of $400 \mathrm{MHz}$. IR spectra were obtained with a Nicolet 210 FTIR. Size exclusion chromatography (SEC) was performed on a Varian ProStar Model 210 equipped with an RI 
refractive index detector. Two PLgel $5 \mu \mathrm{m}$ MIXED-C $600 \mathrm{~mm}$ were used at $70{ }^{\circ} \mathrm{C}$ with a $0.8 \mathrm{~mL}$ $\min ^{-1}$ flow rate of DMF, calibrated using PMMA standards.

\subsection{2 - Physical characterization}

Differential scanning calorimetry (DSC) analyses were performed with a calorimeter DSC1 from Mettler Toledo. The polymer was set in an aluminium pan that was consecutively placed in the measurement heating cell and an empty pan was used as reference. These calorimetric experiments were realised under inert atmosphere with a heating rate fixed at $10{ }^{\circ} \mathrm{C} \min ^{-1}$. The thermo-oxidative stability of the polymer was examined using a TGA Q50 apparatus from TA Instruments ${ }^{\circledR}$ under air flow $\left(25 \mathrm{~mL} \mathrm{~min}^{-1}\right)$. The analysis consisted in registering the weight loss of the sample as a function of temperature from the ambient up to $550{ }^{\circ} \mathrm{C}$. The temperature ramp was set at $10{ }^{\circ} \mathrm{C} \min ^{-1}$. Rheological experiments were performed using a stress-controlled dynamic rheometer (AR2000Ex from TA). This apparatus was equipped with an environmental testing chamber to allow the registering of the complex shear modulus $G^{*}=G^{\prime}+j G^{\prime \prime}$ under precise control of the temperature. The component G', called "storage modulus", represents the mechanical rigidity of the sample (i.e. its elastic contribution) whereas the loss modulus G" relates to the dissipated mechanical energy. The behaviour of the reactive mixture was investigated using a cup-plate geometry that was suitable to characterize an evolutive system from the liquid to the solid state (Scheme 1). The inner diameter of the cup was $25 \mathrm{~mm}$ while the upper plate was much smaller $(10 \mathrm{~mm})$ to prevent undesirable side effects. The spectromechanical behavior of the polymer was characterized with the same rheometer but equipped with parallel plates geometry (diameter $25 \mathrm{~mm}$ ) under fixed temperature and with an angular frequency ranging from $10^{-2}$ to $100 \mathrm{rad} \mathrm{s}^{-1}$ in decreasing mode. Rectangular torsion 
geometry was judged more adapted for characterizing the thermomechanical response of the polymer from the solid state. In this latter case, typical dimensions of the specimens were $40 \mathrm{~mm}$ x $8 \mathrm{~mm}$ x $1 \mathrm{~mm}$. The thermomechanical tests were carried out at a heating rate of $3^{\circ}{ }^{\circ} \mathrm{C} \min ^{-1}$ from $-150{ }^{\circ} \mathrm{C}$ up to the molten state and at a constant oscillating angular frequency $\left(\omega=1 \mathrm{rad} \mathrm{s}^{-1}\right)$. The reproducibility of our rheological results was checked repeating twice our analyses. As regards the polymer $\mathrm{Tg}$, the uncertainty of measurement was found to be $\pm 1{ }^{\circ} \mathrm{C}$

\section{3 - Synthesis of poly(hydroxyurethane)s from DCter and DA10}

$2 \mathrm{~g}$ of DCter $(5.46 \mathrm{mmol})$ and $0.45 \mathrm{~mL}$ of DA10 $(5.46 \mathrm{mmol})$ were introduced in a schlenk under nitrogen flux and solubilized in $4 \mathrm{~mL}$ of freshly distilled DMF. The mixture was stirred during 48 $\mathrm{h}$ at a fixed temperature but ranging from $70{ }^{\circ} \mathrm{C}$ to $120{ }^{\circ} \mathrm{C}$. After completion of the reaction, DMF was removed by evaporation and the residue was dissolved in methanol $(5 \mathrm{~mL})$ and precipitated with diethyl ether $(5 \mathrm{~mL})$. The product was obtained as a white solid. In the case of a reaction temperature of $75^{\circ} \mathrm{C}$, the yield was about $95 \%$.

\footnotetext{
${ }^{1} \mathrm{H}$ NMR $\left(\mathrm{DMSO}_{6}\right) \delta(\mathrm{ppm}):$ 8.11-8.05 $\left(4 \mathrm{H}, \mathrm{CH}_{\mathrm{aro}}\right), 7.18-7.16(2 \mathrm{H}, \mathrm{NH}), 5.37-4.00\left(5 \mathrm{H}_{\mathrm{x}}+5 \mathrm{H}_{\mathrm{y}}\right.$, CH-O and $\left.\mathrm{CH}_{2}-\mathrm{O}\right), 3.57(\mathrm{OH}), 2.92-2.90\left(4 \mathrm{H}, \mathrm{CH}_{2} \mathrm{NH}\right), 1.33-1.18\left(16 \mathrm{H}, \mathrm{CH}_{2}\right.$ of diamine).

${ }^{13} \mathrm{C}$ NMR (DMSO d 6 ) $\delta(\mathrm{ppm}): 164.63\left(\mathrm{C}=\mathrm{O}_{\text {ester }}\right), 155.62\left(\mathrm{C}=\mathrm{O}_{\text {urethane }}\right), 133.31\left(\mathrm{C}_{\text {aro }}\right), 129.26$ $\left(\mathrm{CH}_{\text {aro }}\right)$, 66.10-66.31 $\left(\mathrm{CH}_{2}-\mathrm{O}\right), 64.42(\mathrm{CH}-\mathrm{O}), 39.68\left(\mathrm{CH}_{2}-\mathrm{N}\right), 28.77\left(\mathrm{CH}_{2}\right.$ of diamine $), 26.02$ $\left(\mathrm{CH}_{2}-\mathrm{CH}_{2}-\mathrm{NH}\right)$.

FTIR $(\mathrm{KBr}) v\left(\mathrm{~cm}^{-1}\right): 3338(\mathrm{OH}), 1701(\mathrm{C}=\mathrm{O}$, urethane $), 1542(\mathrm{NH}$, urethane $)$.
} 


\section{3 - Results and Discussion}

\section{1 - Rheological characterization of the reactive mixture in DMF solution}

\subsection{1 - Thermomechanical analysis}

It is well established by now that the polymerization of a reactive mixture can be studied using a large range of experimental methods including differential scanning calorimetry. We used this technique to investigate the reaction between the dicyclocarbonate DCter and diamine DA10 units in DMF. Unfortunately, no exothermic phenomenon was detected in the thermogram from ambient temperature up to $150{ }^{\circ} \mathrm{C}$. Nevertheless, chemical analyses of the sample at the end of the calorimetric experiment made undeniable the transformation from the monomer to the polymer. Consequently, the enthalpy associated to the polymerization was judged too reduced to permit the detection by DSC of the step-growth polyaddition of the comonomers.

Then, a new approach based on the conduction of rheological measurements was explored. A first experiment carried out in dynamic mode consisted in registering the evolution of the rheological behavior of the comonomers in DMF solution as a function of the temperature. Figure 1 presents the results of the analysis conducted from $30{ }^{\circ} \mathrm{C}$ up to $185{ }^{\circ} \mathrm{C}$. In this temperature range, the thermomechanical behavior of the reactive formulation could be divided into five characteristic zones. In the first one ranging from $30{ }^{\circ} \mathrm{C}$ to $75^{\circ} \mathrm{C}$, the viscous character of the solution was predominant $\left(G^{\prime \prime}>G^{\prime}\right)$ and the values of both moduli decreased with temperature as observed with classical viscoelastic fluids (zone (1)). In the following domain that goes from $75{ }^{\circ} \mathrm{C}$ to $100{ }^{\circ} \mathrm{C}$, one could observe that the reduction of $\mathrm{G}^{\prime}$ and $\mathrm{G}$ " was much less marked. In a second step, both moduli even increased with temperature. Due to this evolution, the zone (2) could be interpreted as being characteristic of the step-growth polyaddition between 
DCter and DA10. Indeed, the formation of macromolecular chains was expected to produce an increase of the viscoelastic moduli. The effect was much more significant with the storage modulus because of the progressive increase of the relaxation time of the material. Nevertheless, the polymer in solution presented a rheological response characteristic of a viscoelastic liquid due to the presence of DMF solvent. NMR analyses conducted on samples issued from the reactive mixture submitted to a regular heating were performed to verify the reaction temperature onset. The formation of characteristic bands of the poly(hydroxyurethane) were detected for $\mathrm{T} \sim 75^{\circ} \mathrm{C}$ what appeared consistent with the interpretation of zone (2).

A new reduction of both rheological curves was observed between $100{ }^{\circ} \mathrm{C}$ and $115^{\circ} \mathrm{C}$ (zone (3)). This evolution was likely provoked by a combination of two effects: i) a reduction of the polymerization rate because of the progressive consumption of the monomers and ii) the resume of the thermo-thinning effect. This latter evolution seemed to show that the polymer formed was a thermoplastic. But, in the zone (4) ranging from $115^{\circ} \mathrm{C}$ up to $175^{\circ} \mathrm{C}$, both moduli restarted to continuously rise due to the solvent evaporation. The resulting increase of the polymer concentration also induced a predominancy of the elastic character. For temperatures higher than $175^{\circ} \mathrm{C}$, a rapid increase of both moduli with temperature could be observed once more. At the same time, the color of the molten polymer passed from yellowish to brown and many bubbles appeared. Further TGA analyses performed on poly(hydroxyurethane)s produced at much lower temperature showed that above $170{ }^{\circ} \mathrm{C}$, these phenomena were likely provoked by the polymer degradation.

\section{Insert Figure 1.}

\subsection{2 - Rheological kinetics}

http://mc.manuscriptcentral.com/pi-wiley 
To complete the rheological characterization of the polymerization process, the kinetic of the reaction was analyzed by the conduction of measurements operated under constant shearing frequency and at different fixed temperatures. According to the thermomechanical data previously reported, the polymerization seemed to produce itself at a temperature comprised between $75{ }^{\circ} \mathrm{C}$ and $115{ }^{\circ} \mathrm{C}$. A first kinetic rheological analysis was logically led in this temperature range at $\mathrm{T}=80{ }^{\circ} \mathrm{C}$ (Figure 2). At the beginning of the analysis, the reactive mixture was a viscoelastic liquid $\left(G^{\prime \prime}>G^{\prime}\right)$. Afterwards, the values of both moduli quickly increased with time and even tend towards an asymptotic limit. This evolution could be attributed as being a consequence of the polymer formation: the macromolecular chains were much less mobile than the initial monomers what provoked the increase of the complex shear modulus. At this temperature, the viscous character remained predominant because the polymer was still solubilized in DMF.

\section{Insert Figure 2.}

A new kinetic experiment was performed at higher temperature $\left(\mathrm{T}=100{ }^{\circ} \mathrm{C}\right)$. To make easier the comparison of the corresponding data, we plotted in Figure 3 the evolution of the magnitude of the complex shear modulus $\left|G^{*}\right|=\sqrt{G^{\prime 2}+G^{\prime 2}}$ as a function of the time. For sake of clarity, the only experimental data that are proposed are those which are representative of the first moments of the rheological analysis $(\mathrm{t}<4 \mathrm{~h})$. Compared to the kinetic measurements carried out at $80{ }^{\circ} \mathrm{C}$, the increase of the moduli at $\mathrm{T}=100{ }^{\circ} \mathrm{C}$ occurred at a higher rate. This was attributed to the temperature activation of the reaction between DCter and DA10. 
Then, a last rheological kinetic was undertaken at $\mathrm{T}=120{ }^{\circ} \mathrm{C}$. Even if this temperature was located above the polymerization range determined previously in dynamic mode, the step-growth was judged likely to occur. Apparently, the temperature of $120{ }^{\circ} \mathrm{C}$ did not provide any acceleration of the polymerization process. Indeed, the evolution of the shear modulus in the first times was almost confounded with that registered at $\mathrm{T}=100{ }^{\circ} \mathrm{C}$. This result indicated that a temperature of $120^{\circ} \mathrm{C}$ was likely excessive to guaranty a polymerization process of quality. The higher final value of the modulus was attributed to the solvent evaporation. This phenomenon was considered as an undesirable phenomenon responsible of reduction of the monomers dissolution and consequently their lower reactivity. In other words, better polymerization conditions seemed to be encountered for $\mathrm{T}$ close to $100{ }^{\circ} \mathrm{C}$.

\section{Insert Figure 3.}

\section{2 - Study of the poly(hydroxyurethane)}

The influence of the synthesis parameters was also evaluated by the study of the final properties of the polymer. For this purpose, different poly(hydroxyurethane) samples, A to D, were synthesized at specific temperatures $\mathrm{T}_{\mathrm{p}}$ comprised between $75{ }^{\circ} \mathrm{C}$ and $120{ }^{\circ} \mathrm{C}$ but by keeping constant the reaction time (Table 3). This latter parameter was fixed at $48 \mathrm{~h}$ because this duration was found sufficient to observe the stabilization of the moduli in the different rheological kinetics.

\section{Insert Table 3.}

\subsection{1 - Calorimetric and SEC characterizations}


Calorimetric experiments were undertaken from $-50{ }^{\circ} \mathrm{C}$ to $150{ }^{\circ} \mathrm{C}$ to determine the glass transition temperature of each polymer and investigate the possible presence of a melting zone. An example of thermogram is proposed in Figure $\mathbf{4}$ and concerns the sample B. A discontinuity in the calorimetric signal was interpreted as being characteristic of the polymer glass transition. Taken down at the midpoint, the $\mathrm{Tg}$ was measured at $48{ }^{\circ} \mathrm{C}$. In the temperature domain explored, no endothermic phenomenon, related to the melting of a crystalline phase, was detected. Then, the poly(hydroxyurethane) sample was considered as being fully amorphous. This seemed logical since the material aspect was yellowish and transparent. Similar conclusions were obtained with the other samples A, C and D whatever the conditions used for the synthesis. Nevertheless, little differences could be noted in the values of the glass transition temperature.

\section{Insert Figure 4.}

The higher values of $\mathrm{Tg}$ were obtained for the polymerizations conducted in the range $90-100{ }^{\circ} \mathrm{C}$ (Table 3). A temperature $\mathrm{T}_{\mathrm{p}}=120{ }^{\circ} \mathrm{C}$ seemed excessive since it provoked the formation of a polymer (sample D) with a reduced value of glass transition temperature. These results were consistent with the first conclusions proposed after the rheological kinetic studies. To go further in the scientific discussion, SEC analyses were conducted on the different samples A, B, C and D. The corresponding data, also presented in Table 3, showed that the average number molecular weight of the poly(hydroxyurethane) was closely dependent on the temperature used during the synthesis step. The higher value $\left(\mathrm{M}_{\mathrm{n}}=20000 \mathrm{~g} \mathrm{~mol}^{-1}\right)$ was obtained with the temperature of 90 ${ }^{\circ} \mathrm{C}$ (sample B). But, this synthesis temperature also produced at the same time a maximal polydispersity index $\mathrm{I}_{\mathrm{p}}$. At $\mathrm{T}_{\mathrm{p}}=120^{\circ} \mathrm{C}$, the value of the molecular weight was much lower $(8000$ $\mathrm{g} \mathrm{mol}^{-1}$ ) bearing out that this temperature was less convenient for the polymer synthesis due to 
the parasitic evaporation of the solvent. In fact, all these data agreed with the hierarchy proposed previously from the rheological and calorimetric experiments.

\title{
3.2.2 - Rheological properties of the poly(hydroxyurethane) samples
}

Further characterization of the different samples of poly(hydroxyurethane) focused on the evolution of their viscoelastic properties as a function of temperature. Figure $\mathbf{5}$ shows as example the thermomechanical profile registered with the polymer synthesized at $90{ }^{\circ} \mathrm{C}$ (sample B). This rheological analysis indubitably showed that the poly(hydroxyurethane) was an amorphous thermoplastic polymer. Indeed, different characteristic zones were successively observed. In the low temperature region $\left(\mathrm{T}<40^{\circ} \mathrm{C}\right)$, the material was in the glassy state $\left(\mathrm{G}^{\prime} \sim 10^{9} \mathrm{~Pa}\right)$. Afterward, the curve of the elastic modulus G' showed a deflection while the G" curve presented a relaxation peak. Both phenomena were attributed to the mechanical relaxation of the amorphous chains during the glass transition of the polymer. The polymer Tg could be evaluated by taking the temperature at the maximum of the peak on the G".

\section{Insert Figure 5.}

\begin{abstract}
Above this critical temperature, the decrease of the shear modulus with temperature was important but the elastic response became again predominant in the temperature ranging from $\mathrm{T}=$ $58{ }^{\circ} \mathrm{C}$ up to $\mathrm{T}=81{ }^{\circ} \mathrm{C}$. This domain, characteristic of the rubbery zone of the polymer, revealed that the polymer chains constituting the sample B presented an average molecular weight that was high enough to permit the formation of entanglements. ${ }^{[31,32]}$ The molecular weight between entanglements $\mathrm{M}_{\mathrm{e}}$ in this temporary network could be evaluated according to the classical theory of rubber elasticity and using the following equation: ${ }^{[33,34]}$
\end{abstract}




$$
\mathrm{M}_{\mathrm{e}}=\rho \mathrm{RT} / \mathrm{G}_{\mathrm{r}}^{\prime}
$$

where $\rho$ is the polymer density (taken close to $\left.1000 \mathrm{~kg} \cdot \mathrm{m}^{-3}\right), \mathrm{R}$ the gas constant $\left(8.31 \mathrm{~J} \mathrm{~mol}^{-1} \mathrm{~K}^{-1}\right)$, $\mathrm{G}_{\mathrm{r}}^{\prime}$ the value of the elasticity taken down at the middle of the rubbery zone and $\mathrm{T}$ the corresponding temperature. Finally, the flow zone of the polymer, characterized by G" > G', was observed for $\mathrm{T}>81^{\circ} \mathrm{C}$. No crystalline plateau was detected during the thermomechanical analysis. Then, considering that this polymer should verify the equivalency time-temperature, spectromechanical analyses were carried out at various fixed temperatures. Taking as a reference that registered at the lowest temperature $\left(\mathrm{T}=55^{\circ} \mathrm{C}\right)$, a master curve could be easily built by translation of the other analyses along the $\omega$-axis (Figure 6). This analysis made it possible the plain description of the different domains previously detected by the thermomechanical experiment. Actually, the rheological behavior initially detected at high temperature was observed at low frequency and vice-versa. ${ }^{[31]}$ At $\omega<310^{-3} \mathrm{rad} \mathrm{s}^{-1}$, the flow zone of the polymer was clearly shown. The rubbery zone was identified for $\omega$ ranging from $310^{-3}$ to $1.510^{-1} \mathrm{rad} \mathrm{s}^{-1}$. For higher $\omega$ values, the increase of both moduli was characteristic of the transition zone. The thermoplastic and amorphous characters of DCter-DA10 PHU were considered as indisputable. In that sense, this PHU was considered as quite different from the poly(hydroxyurethane)s developped by Javni ${ }^{[35]}$, Diakoumakos ${ }^{[36]}$, or Webster. ${ }^{[37]}$ It resembled more to the class of PHUs proposed by Kihara ${ }^{[21]}$ or Rokicki. ${ }^{[38]}$

\section{Insert Figure 6.}

The characterization of the thermomechanical response of the other poly(hydroxyurethane) samples (A, C and D) led to the same conclusions about the polymer morphology (Figure 7). 
However, the glass transition temperature taken down at the maximum of G" curve differed from one sample to the other. The different values remained close to that obtained previously by calorimetry (Table 3). A direct confrontation of our results with that reported in the literature was considered as really interesting. In particular, we chose to use the data summarized in Table 2 because they were registered with PHUs made with the same dicyclocarbonate DCter. The only difference was brought by the diamine length. Our material was based on 1-10-diaminodecane that was expected to be logically more flexible than 1-3-diaminopropane and 1-6 diaminohexane used by Steblyanko. ${ }^{[4]}$ In other words, our polymer would have to present the lowest Tg but the reverse case was observed. This result confirmed the necessity to investigate for each kind of PHU, the best conditions of time and temperature used during the synthesis step. As evidence, these latter factors should not be considered as universal parameters.

\section{Insert Figure 7.}

Going further in the description of the samples A to D, one could note that the trend established from the Tg values agreed with the classification that can be built from the SEC data (Table 3). More precisely, the evolution of the PHUs' Tg as a function of the average molecular weight M was satisfactorily described using the equation (2) initially proposed by Fox and Flory but modified by Bicerano: ${ }^{[39]}$

$$
\operatorname{Tg}=\operatorname{Tg}(\infty)-2.715 \times \operatorname{Tg}(\infty)^{3} / \mathrm{M}
$$

where $\operatorname{Tg}(\infty)$, expressed in Kelvin, is the value of $\mathrm{Tg}$ for very high molecular weight and $\mathrm{M}$ the average molecular weight $\left(\mathrm{kg} \mathrm{mol}^{-1}\right)$. 
The best adjustment of the experimental data in Figure 8 with eq. 2 was obtained with $\operatorname{Tg}(\infty)=$ $325 \mathrm{~K}=52{ }^{\circ} \mathrm{C}$. This latter value was evaluated quite close to the $\mathrm{Tg}$ of the sample $\mathrm{B}\left(\mathrm{Tg}=48{ }^{\circ} \mathrm{C}\right)$ assessing once more that this PHU was synthesized with excellent conditions of temperature and time.

\section{Insert Figure 8.}

Besides the glass transition temperature, the value of molecular weight also influenced the existence and the size of the rubbery zone. As defined before, this domain was encountered for the polymer B from $58{ }^{\circ} \mathrm{C}$ to $79{ }^{\circ} \mathrm{C}$ and at a lower extent for the sample $\mathrm{C}$ from $56{ }^{\circ} \mathrm{C}$ up to $70{ }^{\circ} \mathrm{C}$ (Figure 7). In other words, the rubbery zone was more extended of $7^{\circ} \mathrm{C}$ in the case of sample B in comparison with polymer $\mathrm{C}$. This seemed logical since the former was characterized by a higher molecular weight. Anyway, this experimental temperature difference $\triangle \mathrm{T}=7^{\circ} \mathrm{C}$ agreed with the value calculated using the Equation 3: ${ }^{[31]}$

$$
\Delta \mathrm{T}=100 \times \log \left(\mathrm{M}_{\mathrm{B}} / \mathrm{M}_{\mathrm{C}}\right)
$$

with $M_{B}$ and $M_{C}$ are the respective average weights of the poly(hydroxyurethane)s $B$ and $C$. Inversely, the rubbery state was not observed for the polymers of lowest molecular weights (samples A and D). If it is well-known that entanglements can only be formed if the polymer size exceeds a critical size, the exploitation of the specific data of the sample B was considered as useful to estimate the threshold value. The elastic modulus taken at the middle of the rubbery zone presented a value $\mathrm{G}_{\mathrm{r}}^{\prime}=5.710^{5} \mathrm{~Pa}$ at $\mathrm{T}=63{ }^{\circ} \mathrm{C}=336 \mathrm{~K}$. Considering that the polymer density was unity, the molecular weight between entanglements $M_{e}$ calculated according to equation (1) is close to $5000 \mathrm{~g} \mathrm{~mol}^{-1}$. Then, the critical number-molecular weight $\mathrm{M}_{\mathrm{c}}$ above which 
entanglements were possible could be evaluated according to Graessley theory: $\mathrm{M}_{\mathrm{c}}=2.5 \mathrm{M}_{\mathrm{e}}=$ $12500 \mathrm{~g} \mathrm{~mol}^{-1} \cdot{ }^{[40-42]}$ This result is worthy of note because it seemed to be able to justify why the samples B and C, characterized by an average number molecular weight $M_{n}>M_{c}$, were the only ones to present a rubbery plate. Once more, the synthesis temperature $\mathrm{T}_{\mathrm{p}}$ conducting to a polymer with enhanced mechanical properties was found to be close to $90{ }^{\circ} \mathrm{C}$ with a synthesis period of 48h. 


\section{4 - Conclusion}

This paper proposed an original methodology based on dynamic rheometry in order to determine the best synthesis conditions attached to a PHU produced from the reaction between DCter and DA10 polymer. A first way consisted in using the rheometer as an instrumented reactor to investigate with dedicated experiments, the temperature domain and the kinetic characteristic of the step-growth polyaddition. It quickly showed that the polymerization required a minimal temperature close to $80^{\circ} \mathrm{C}$. At the same time, the reaction should not be carried beyond $120^{\circ} \mathrm{C}$ due to the beginning of the solvent evaporation. The second approach investigated the thermomechanical characterization of different poly(hydroxyurethane)s prepared with the same co-monomers but according to arbitrary conditions. It presented the great advantage to furnish useful information to evaluate the quality of the final PHU. If the glass transition temperature could be used as a reliable criterion, our research showed that the characteristics of the rubbery zone earned to be exploited in terms of molecular weight. These results allowed the accurate definition of the time and temperature conditions that had to be retained during the synthesis step in order to produce a PHU with optimal properties. Both rheological methods agreed to designate the synthesis temperature of $90^{\circ} \mathrm{C}$ as ideal for the production of polymer chains with high molecular weight. If the viscoelastic data agreed with the results obtained separately by SEC analyses and DSC techniques, it is important to remind that rheometry offered a more complete description of the poly(hydroxyurethane). Ultimately, the good correspondence between experience and several theoretical concepts was considered as another evidence of the effectiveness of the method. The possible application of this rheological methodology to other dicyclocarbonate-diamine couples will be examined in a future work. 


\section{References}

1. Verheugen G, Off J of Eur Union, L 164/7-L164/9 (2009)

2. Whelan JM, Hill M and Cotter RJ, US Patent 3072613 (1963).

3. Mikheev VV, Svetlakov NV, Sysoev VA and Gumerora RK, Zh. Org Khim 19: 498-501 (1983).

4. Steblyanko A, Choi W, Sanda F and Endo T, J Polym Sci: Part A: Polym Chem 38: 23752380 (2000).

5. Shaikh A and Sivaram S, Chem Rev 96: 951-976 (1996).

6. Zhao F, CN Patent 101376632 A 20090304 (2009).

7. Crawford WC, Marquis ET and Klein HP, US Patent 5340889 (1994).

8. December TS and Harris PJ, US Patent 5431791 (1995).

9. Koenraadt MA, Noomen A, Van den Berg K, Klinkenberg H and Hobel K, WO Patent 9724408 (1997).

10. Tomita H, Sanda F and Endo T, J Polym Sci: Part A: Polym Chem 39: 860-867 (2001).

11. Tomita H, Sanda F and Endo T, J Polym Sci: Part A: Polym Chem 39: 162-168 (2001).

12. Tomita H, Sanda F and Endo T, J Polym Sci: Part A: Polym Chem 39: 4091-4100 (2001).

13. Yeo IS, Woo BW, Yoon SW, Lee JH, Park SH and Jang NJ. US Patent 2010048918 (2010).

14. Bhanage BM, Fujita SI, Ikushima Y and Arai M, Green Chemistry 5: 429-432 (2003).

15. Claude S, Mouloungui Z, Yoo Jeong W and Eugene GA, US Patent 6025504 (2000).

16. Ubaghs L, Fricke N, Keul H and Höcker H, Macromol. Rapid Com. 25: 517-521 (2004).

17. Diakoumakos CD and Kotzev DL, WO Patent 2005016993 (2005).

18. Figovsky O and Shapovalov L, Macromol Symp, 187: 325-332 (2002). 
19. Figovsky O, Shapovalov L, Blank N and Buslov F, US2004192803 (2004)

20. Tomita H, Sanda F and Endo T, J Polym Sci: Part A: Polym Chem 39: 851-859 (2001).

21. Kihara N and Endo T, J of Polym Sci Part A Polym Chem 31: 2765-2773 (1993).

22. Tomita H, Sanda F and Endo T, J of Polym Sci Part A Polym Chem 39: 3678-3685 (2001).

23. Burgel T and Fedtke M, Polym Bull 30: 61-68 (1993).

24. Kim MR, Kim HS, Ha CS, Park DW and Lee JK, J Appl Polym Sci 81: 2735-2743 (2001).

25. Ochiai B, Nakayama JI, Mashiko M, Kaneko Y, Nagasawa T and Endo T, J of Polym Sci Part A Polym Chem, 43: 5899-5905 (2005).

26. Husken D, Krijgsman J and Gaymans RJ, Polymer, 45: 4837-4843 (2004).

27. Lu XZ, Lian YQ, Wang XG, Zhou QX and Liu DS, Chinese Journal of Polymer Science, 19 (1): 103-106 (2001).

28. Villasenor P, Franco L and Puiggali J, Polymer, 40 (24): 6887-6892 (1999).

29. Joel D, Pohl G and Hiller WG, Angewandte Makromolekulare Chemie, 208: 107-116 (1993)

30. Lachowicz A and Grahe G, DE Patent 3937116 A1 19910508 (1991).

31. Ferry JD, in Viscoelastic properties of polymers, 2nd edition, Wiley \& Sons, New-York (1969).

32. Treloar LRG, in The physics of rubber elasticity, 3rd edition, Charendon, Oxford (1975).

33. Everaers R and Kremer K, Macromolecules, 28: 7291-7294 (1995).

34. Cohen Addad JP, in Polymères, la matière plastique, ed. Belin: Paris, Ch. 3, 64-72 (2007).

35. Javni I, Hong DP and Petrovic ZS, J of Appl Polym Sci, 108: 3867-3875 (2008).

36. Diakoumakos CD and Kotzev DL, Macromol Symp, 216: 37-46 (2004).

37. Webster DC, Progress in Organic Coatings, 47: 77-86 (2003). 
38. Rokicki G and Piotrowska A, Polymer, 43: 2927-2935 (2002).

39. Bicerano J, in Prediction of Polymer Properties, Marcel Dekker, New York, , Ch. 6, $3^{\text {rd }}$ Ed. (2002)

40. Graessley WW, in Physical properties of polymers, Cambridge University Press, $3^{\text {rd }}$ Ed. Ch. 3, 153-208 (2003).

41. Fetters LJ, Lohse DJ, Milner ST and Graessley WW, Macromolecules, 32: 6847-6851 (1999).

42. Kausch HH, Heymans N, Plummer CJ and Decroly P, in Matériaux polymères: propriétés mécaniques et physiques, Presses polytechniques et universitaires romandes, Ch. 8, 243-254 (2001). 


\section{CAPTIONS}

Figure 1. Effect of the temperature on the rheological properties of the reactive mixture $\left(\mathrm{G}^{\prime}: \bigcirc\right.$ and $\left.\mathrm{G}^{\prime \prime}: \mathbf{\Delta}\right)$.

Figure 2. Evolution of the viscoelastic properties of the reactive mixture versus time at $\mathrm{T}=80^{\circ} \mathrm{C}$ and $\omega=10 \mathrm{rad} \mathrm{s}^{-1}$ with $\mathrm{G}^{\prime}:(\bullet .$.$) and \mathrm{G}^{\prime \prime}:(-)$.

Figure 3. Superposition of the evolution of the magnitude of the complex shear modulus of the reactive mixture as a function of time at three different temperatures $\mathrm{T}_{\mathrm{p}}\left(80^{\circ} \mathrm{C}: \square ; 100^{\circ} \mathrm{C}: \boldsymbol{\Delta}\right.$; $\left.120^{\circ} \mathrm{C}: \bullet\right)$ and $\omega=10 \mathrm{rad} \mathrm{s}^{-1}$.

Figure 4. Calorimetric analysis of the poly(hydroxyurethane) $B$ as a function of temperature (synthesis conditions: $48 \mathrm{~h}$ at $90^{\circ} \mathrm{C}$ )

Figure 5. Thermomechanical analysis of the poly(hydroxyurethane) B with G': $\bullet$ and G": $\triangle$ Figure 6. Master curve of the poly(hydroxyurethane) B built from three spectromechanical analyses: $55^{\circ} \mathrm{C}$ (reference), $75^{\circ} \mathrm{C}$ and $115^{\circ} \mathrm{C}$.

Figure 7. Influence on the synthesis parameters on the final thermomechanical properties of the poly(hydroxyurethane). (the curves are arbitrarily shifted along a vertical axis for clarity, G': and $\mathrm{G}^{\prime \prime}: \triangle$ )

Figure 8. Evolution of the Tg of the DCter-DA10 PHU as a function of the average molecular weight. The symbols correspond to the experimental data while the solid line is given by Eq. 2

Scheme 1. Implementation of rheometry at the different stages of poly(hydroxyurethane) synthesis by reaction of DCter with DA10.

Table 1. Influence of the diamine length on the $\mathrm{Tg}$ of PHU based on a same aliphatic cyclocarbonate 
Table 2. Tg values characteristic of PHUs obtained by the reaction of a same aromatic dicyclocarbonate with different aliphatic diamines

Table 3. Synthesis conditions and properties of the different samples of DCter-DA10 poly(hydroxyurethane) 


\section{For Table of Contents Use Only}

Optimization of the synthesis of poly(hydroxyurethane)s using dynamic rheometry.

Sofia Benyahya, Bernard Boutevin, Sylvain Caillol, Vincent Lapinte, Jean-Pierre Habas*

The temperature and time of polymerization reactions

that lead to poly(hydroxyurethane)s with optimal properties have been determined according to rheological studies.

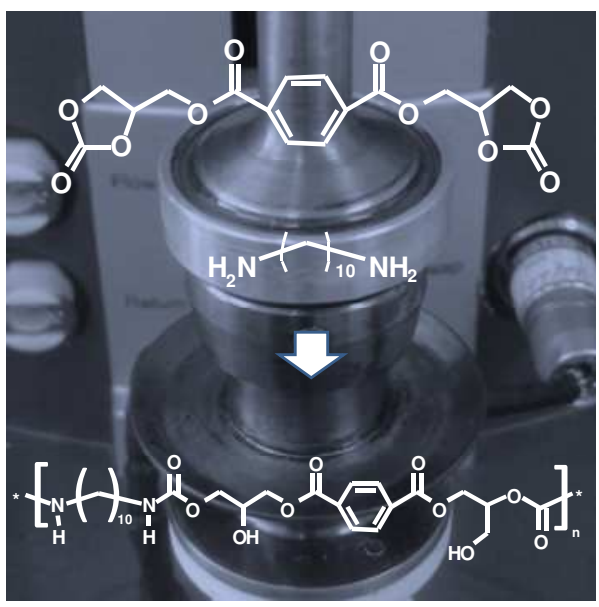

http://mc.manuscriptcentral.com/pi-wiley 


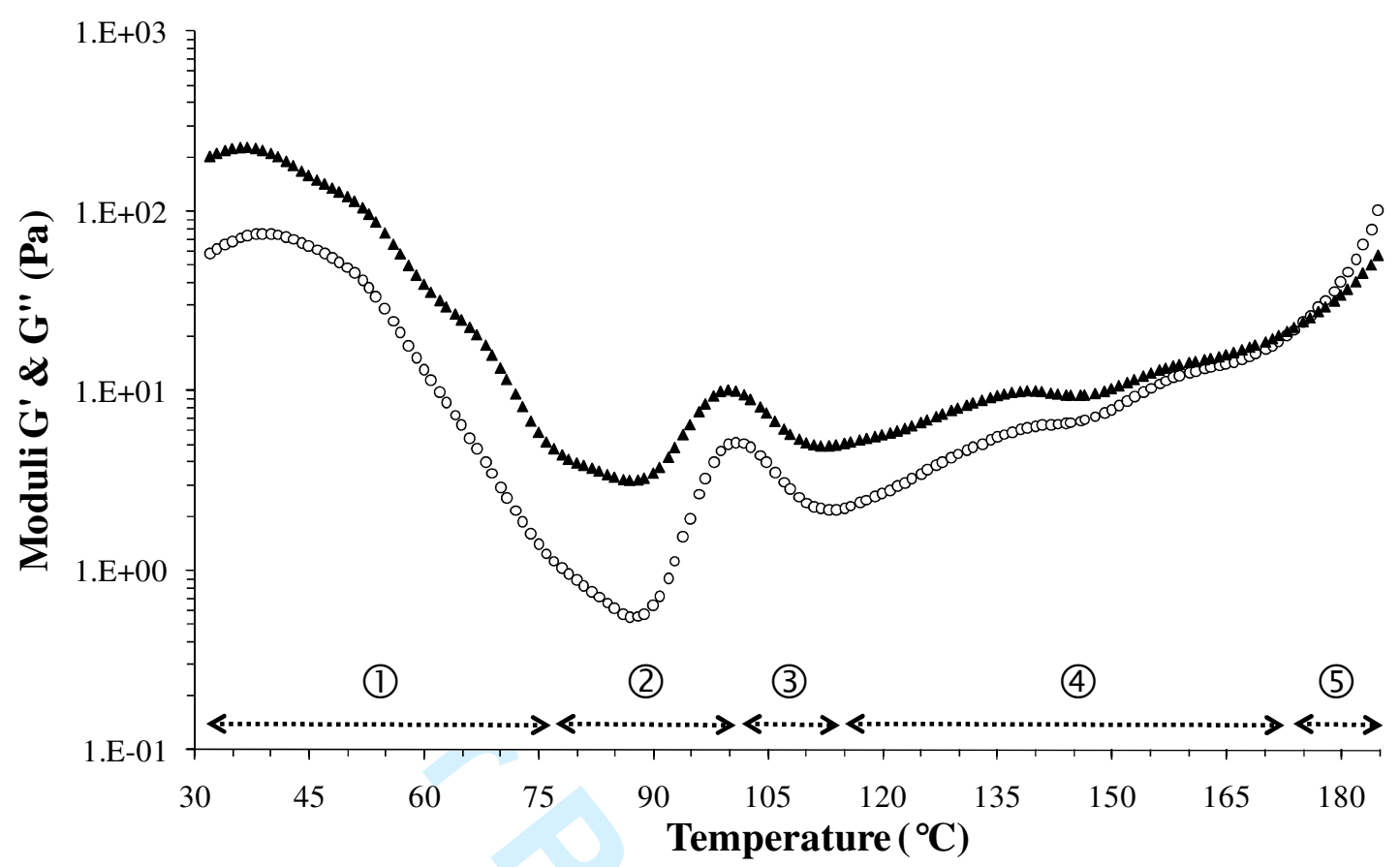

Figure 1. Effect of the temperature on the rheological properties of the reactive mixture $\left(G^{\prime}\right.$ : O and G": $\mathbf{\Delta})$. 
1

2

3

4

5

6

7

8

9

10

11

12

13

14

15

16

17

18

19

20

21

22

23

24

25

26

27

28

29

30

31

32

33

34

35

36

37

38

39

40

41

42

43

44

45

46

47

48

49

50

51

52

53

54

55

56

57

58

59

60

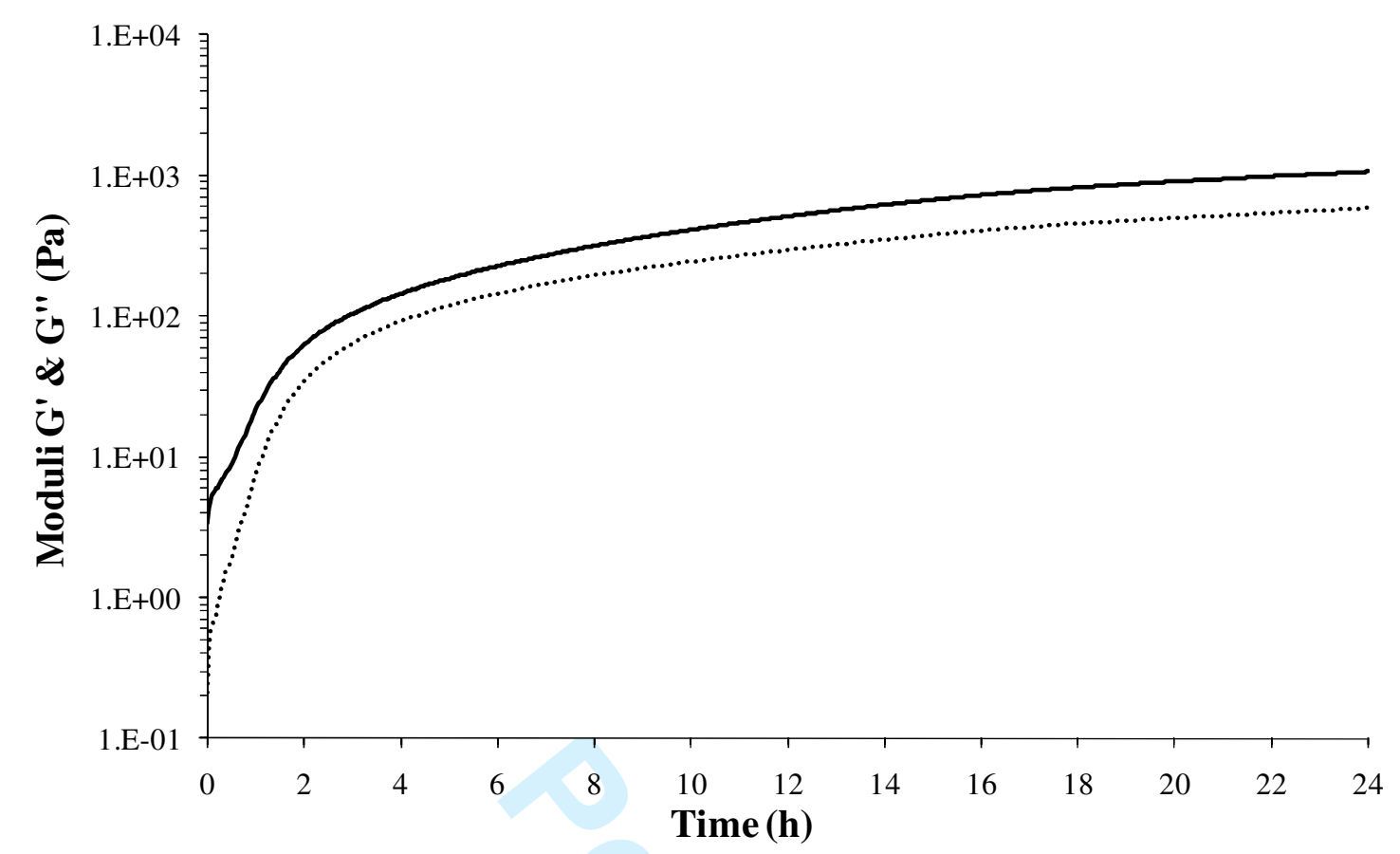

Figure 2. Evolution of the viscoelastic properties of the reactive mixture versus time at $\mathrm{T}=$ $80^{\circ} \mathrm{C}$ and $\omega=10 \mathrm{rad} \mathrm{s}^{-1}$ with $\mathrm{G}^{\prime}:(. .$.$) and \mathrm{G}^{\prime \prime}:(-)$. 


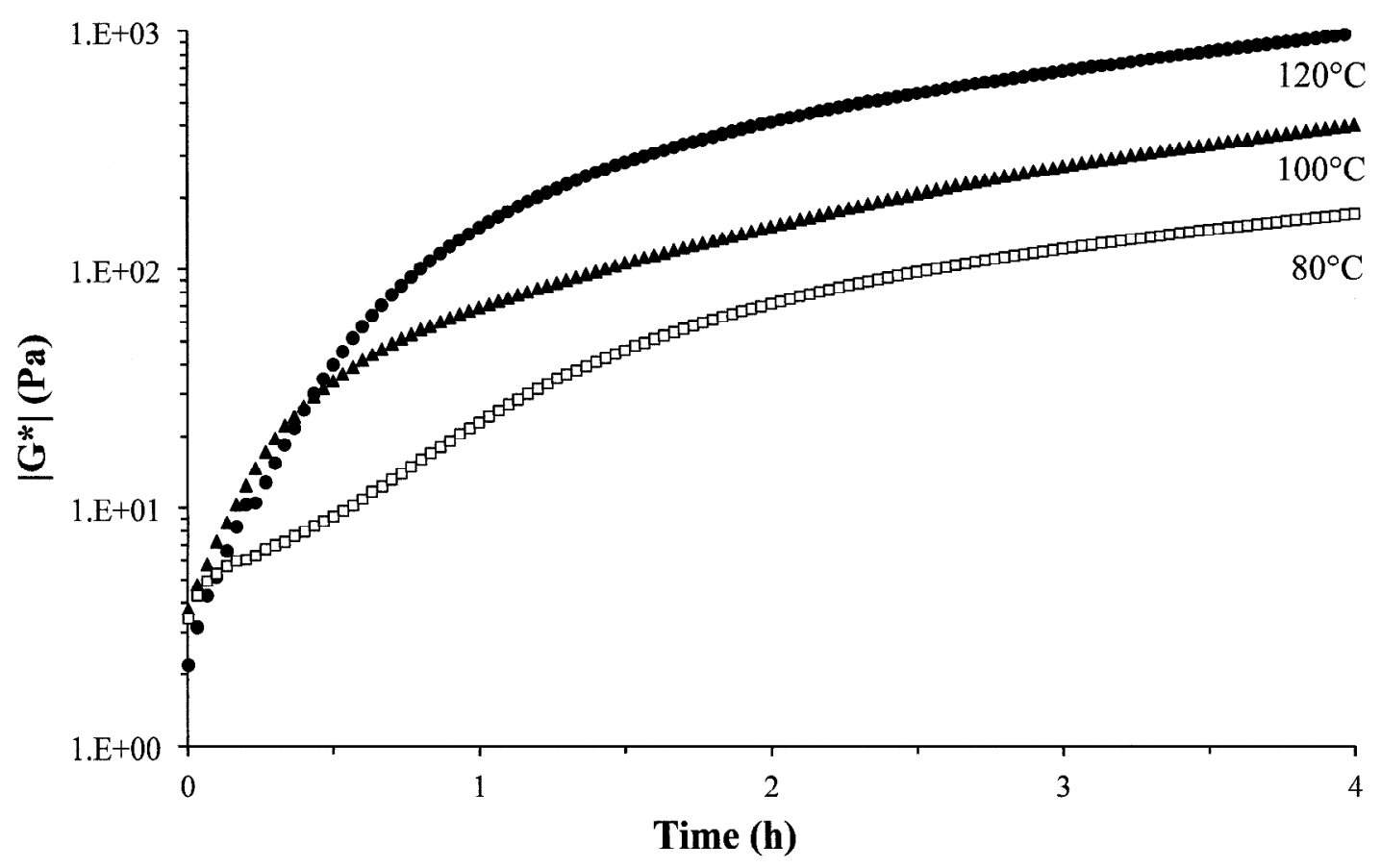

Figure 3. Superposition of the evolution of the magnitude of the complex shear modulus of the reactive mixture as a function of time at three different temperatures $\mathrm{T}_{\mathrm{p}}\left(80^{\circ} \mathrm{C}: \square-100^{\circ} \mathrm{C}\right.$ : $\left.\Delta-120^{\circ} \mathrm{C}: \bullet\right)$ and $\omega=10 \mathrm{rad} \mathrm{s}^{-1}$. 
1

2

3

4

5

6

7

8

9

10

11

12

13

14

15

16

17

18

19

20

21

22

23

24

25

26

27

28

29

30

31

32

33

34

35

36

37

38

39

40

41

42

43

44

45

46

47

48

49

50

51

52

53

54

55

56

57

58

59

60

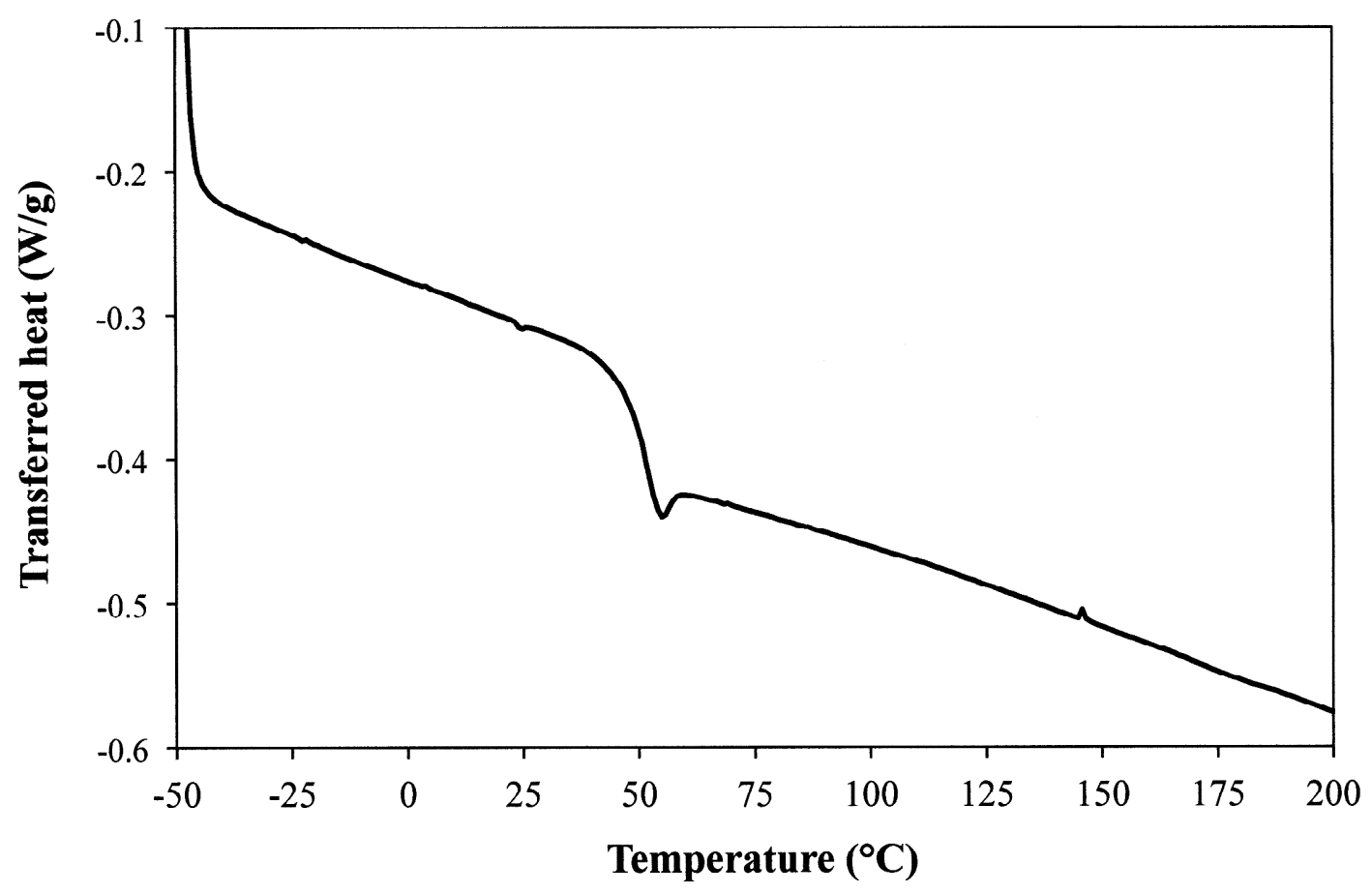

Figure 4. Calorimetric analysis of the poly(hydroxyurethane) B as a function of temperature (synthesis conditions: $48 \mathrm{~h}$ at $90^{\circ} \mathrm{C}$ ) 


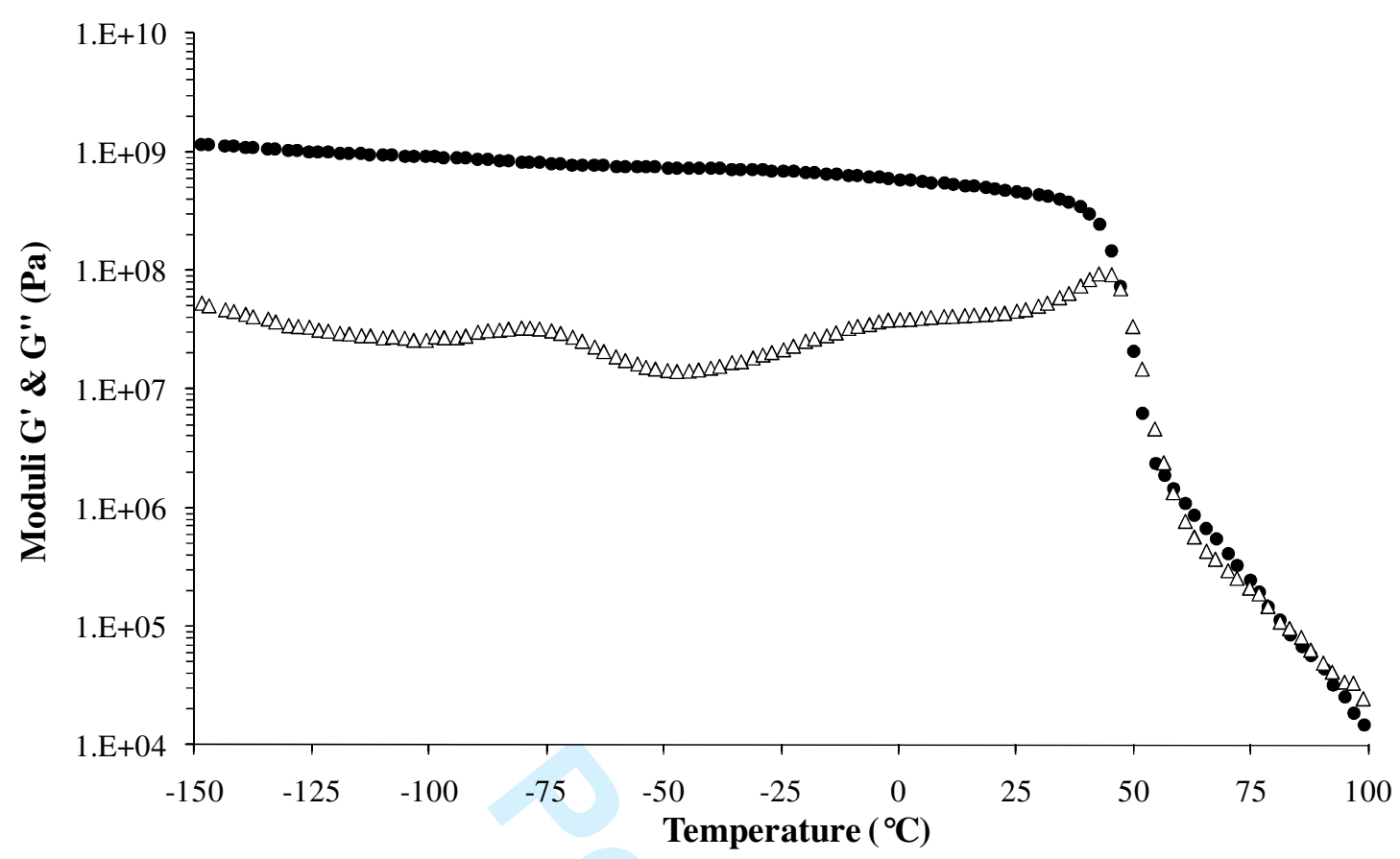

Figure 5. Thermomechanical analysis of the poly(hydroxyurethane) B with G': $\bullet$ and $G^{\prime \prime}: \triangle$ 


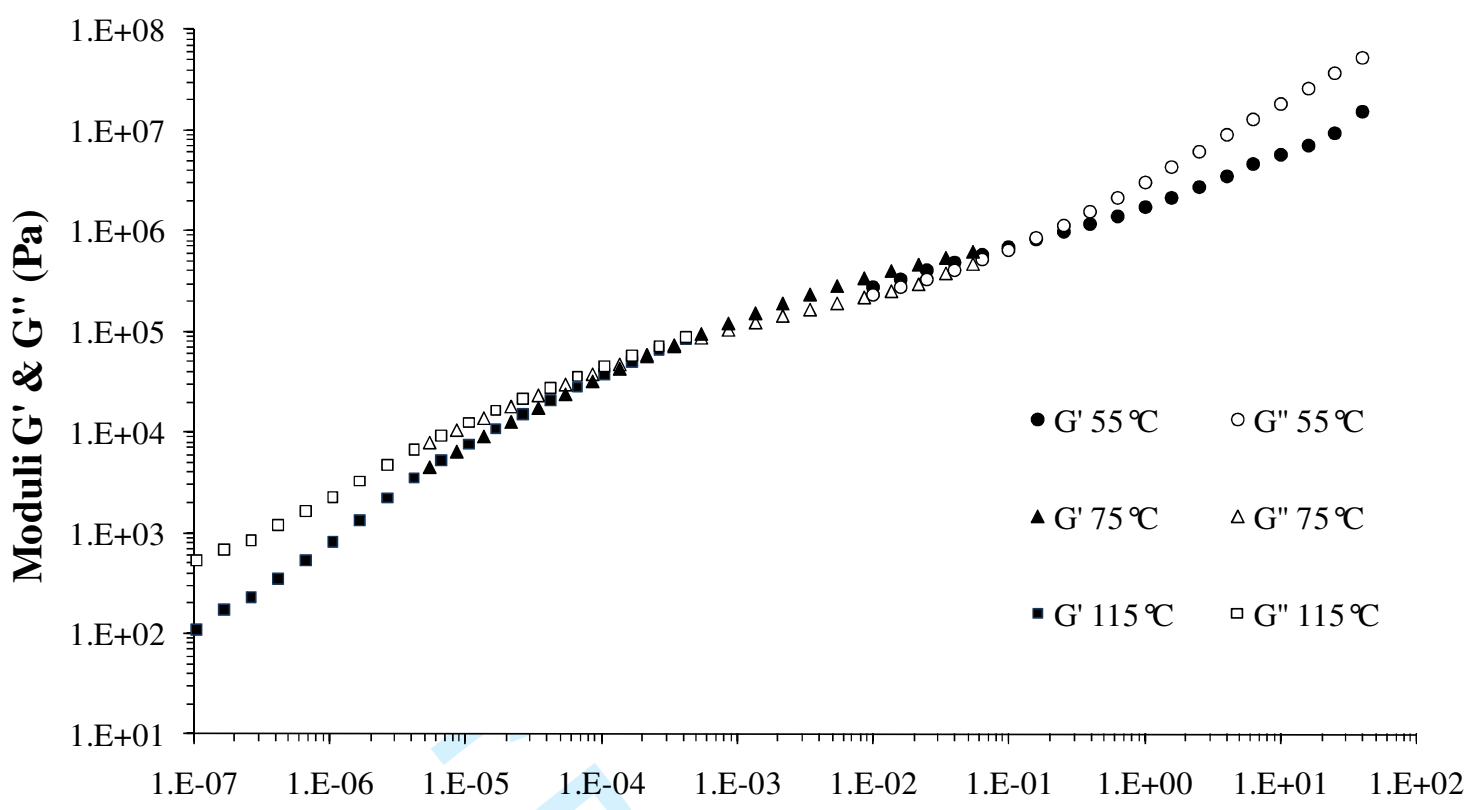

\section{Angular frequency ( $\mathrm{rad} / \mathrm{s})$}

Figure 6. Master curve of the poly(hydroxyurethane) B built from three spectromechanical analyses: $55^{\circ} \mathrm{C}$ (reference), $75^{\circ} \mathrm{C}$ and $115^{\circ} \mathrm{C}$. 


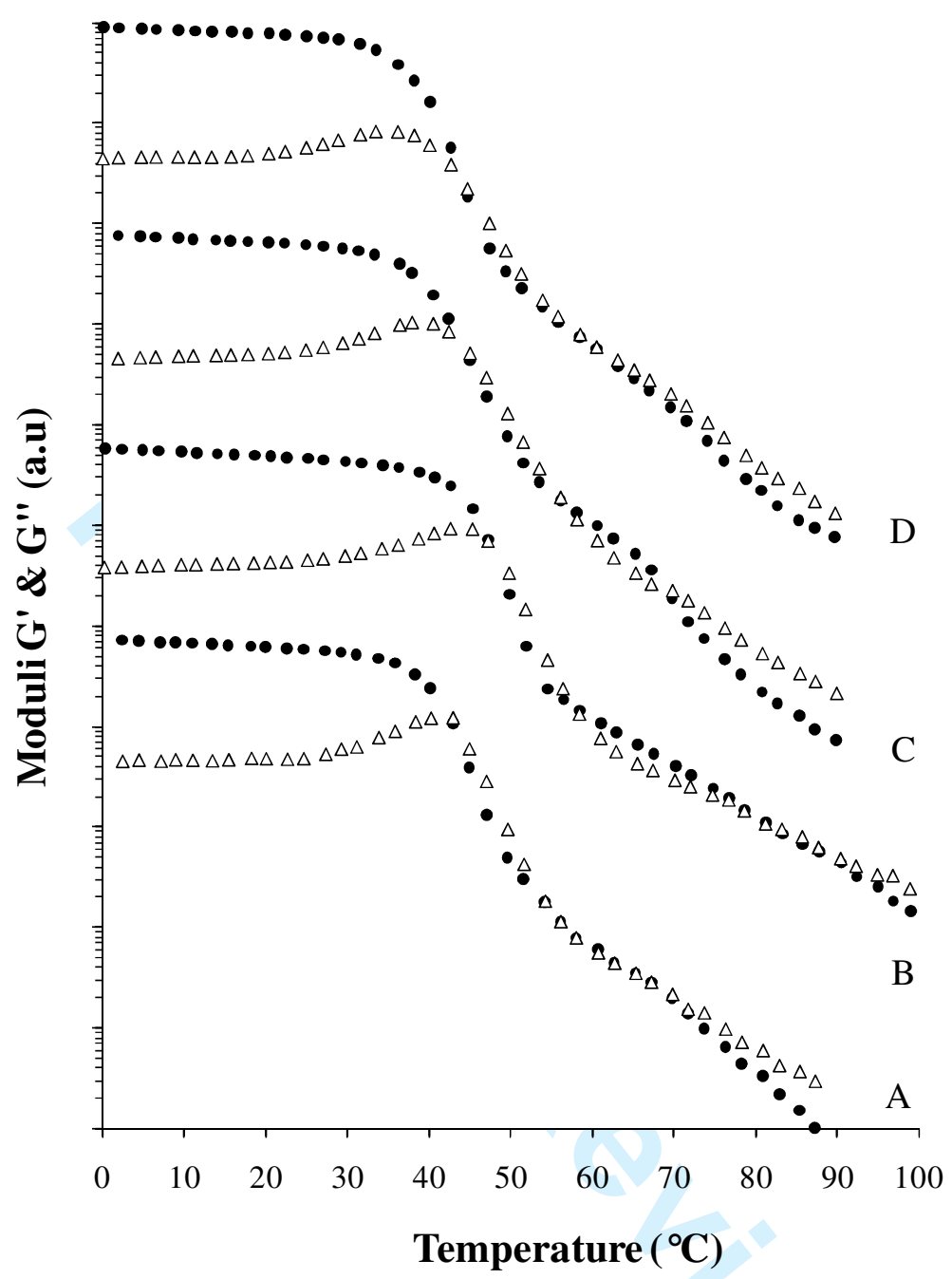

Figure 7. Influence on the synthesis parameters on the final thermomechanical properties of the poly(hydroxyurethane). The curves are arbitrarily shifted along a vertical axis for clarity, $\mathrm{G}^{\prime}: \bullet$ and $\mathrm{G}^{\prime \prime}: \triangle$, and the letters refer to samples designated in Table 3. 
1

2

3

4

5

6

7

8

9

10

11

12

13

14

15

16

17

18

19

20

21

22

23

24

25

26

27

28

29

30

31

32

33

34

35

36

37

38

39

40

41

42

43

44

45

46

47

48

49

50

51

52

53

54

55

56

57

58

59

60

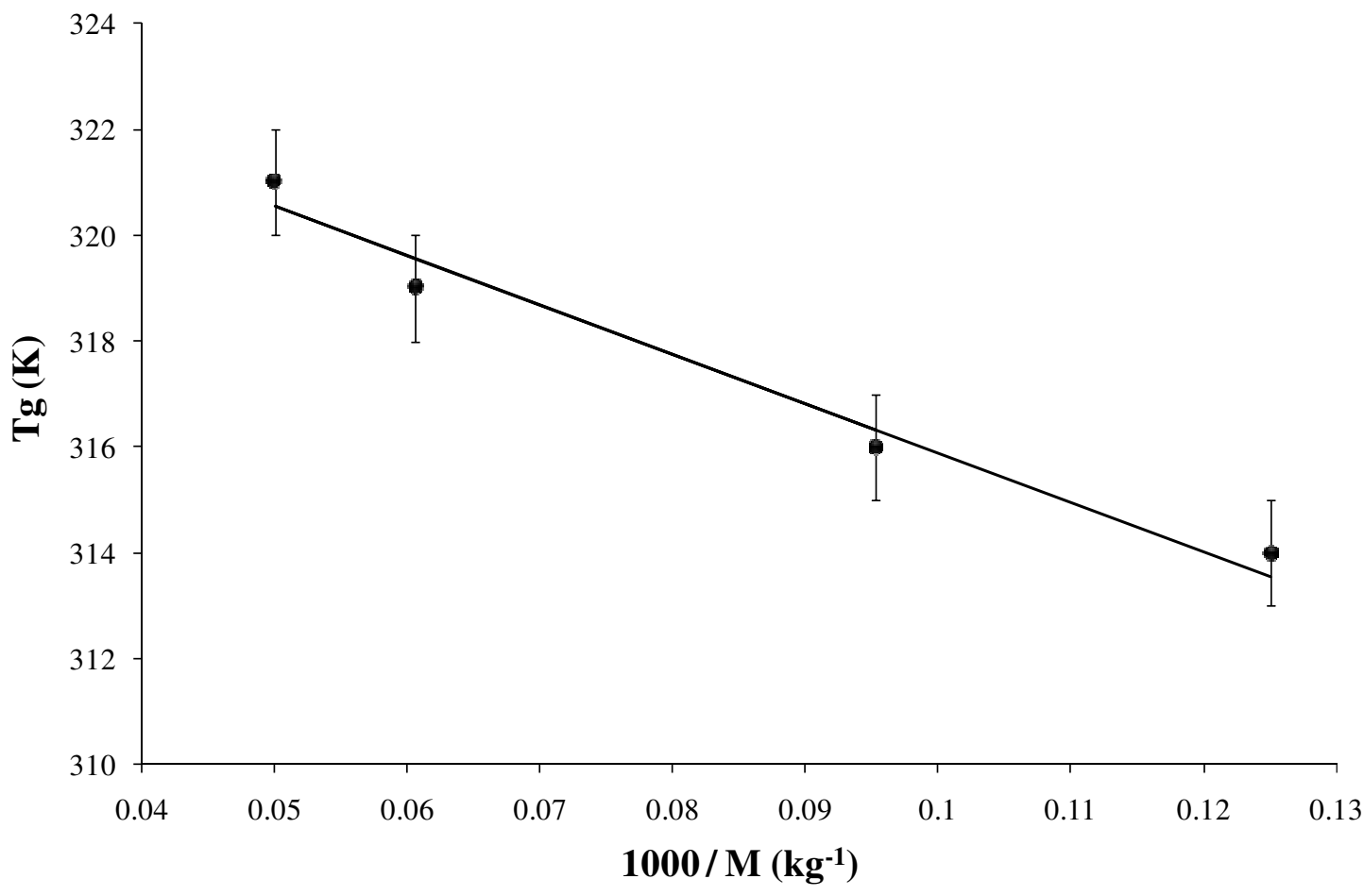

Figure 8. Evolution of the Tg of the DCter-DA10 PHU as a function of the average molecular weight. The symbols correspond to the experimental data while the solid line is given by Eq. 2 
Scheme 1

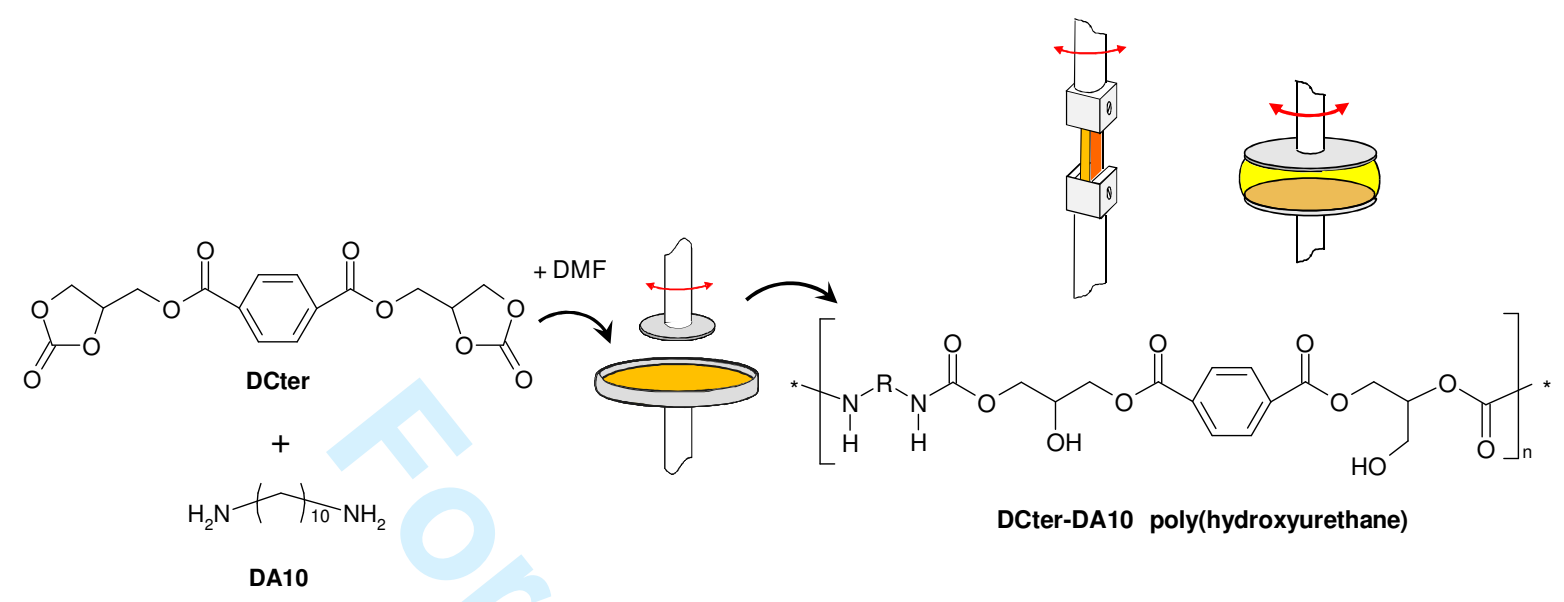

Scheme 1. Implementation of rheometry at the different stages of poly(hydroxyurethane) synthesis by reaction of DCter with DA10. 
1

2

3

4

5

6

7

8

9

10

11

12

13

14

15

16

17

18

19

20

21

22

23

24

25

26

27

28

29

30

31

32

33

34

35

36

37

38

39

40

41

42

43

44

45

46

47

48

49

50

51

52

53

54

55

56

57

58

59

60

Table 1. Influence of the diamine length on the $\mathrm{Tg}$ of PHU based on a same aliphatic cyclocarbonate

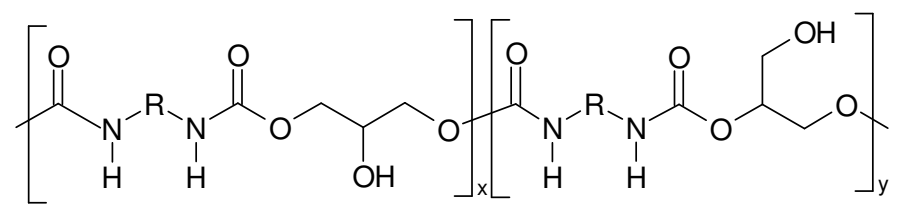

\begin{tabular}{cccccc}
\hline $\mathbf{R}$ & $\left(\mathbf{C H}_{2}\right)_{\mathbf{2}}$ & $\left(\mathbf{C H}_{2}\right)_{\mathbf{3}}$ & $\left(\mathbf{C H}_{\mathbf{2}}\right)_{\mathbf{4}}$ & $\left(\mathbf{C H}_{\mathbf{2}}\right)_{\mathbf{5}}$ & $\left(\mathbf{C H}_{\mathbf{2}}\right)_{\mathbf{6}}$ \\
\hline $\mathbf{T g}\left({ }^{\circ} \mathbf{C}\right)^{\text {a) }}$ & 53 & 45 & 42 & 37 & 23 \\
\hline
\end{tabular}

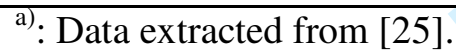


Table 2. Tg values characteristic of PHUs obtained by the reaction of a same aromatic dicyclocarbonate with different aliphatic diamines

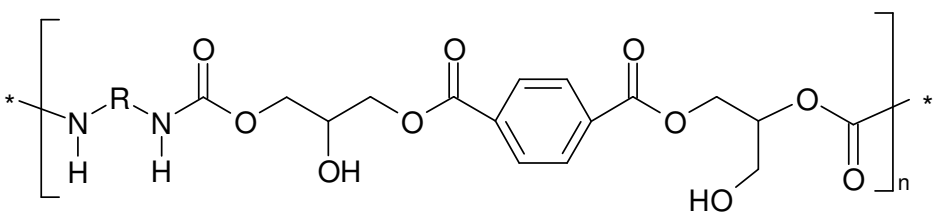

\begin{tabular}{cccc}
\hline $\mathbf{R}$ & $\left(\mathbf{C H}_{2}\right)_{\mathbf{2}}$ & $\left(\mathbf{C H}_{2}\right)_{\mathbf{3}}$ & $\left(\mathbf{C H}_{\mathbf{2}}\right)_{\mathbf{6}}$ \\
\hline $\mathbf{T g}\left({ }^{\circ} \mathbf{C}\right)^{\text {a) }}$ & 21 & 29 & 3 \\
\hline${ }^{\text {a)}}$ : Data extracted from [4]. & &
\end{tabular}


Table 3. Synthesis conditions and properties of the different samples of DCter-DA10 poly(hydroxyurethane)

\begin{tabular}{cccccc}
\hline Sample & $\begin{array}{c}\mathbf{T}_{\mathbf{p}} \\
\left({ }^{\circ} \mathbf{C}\right)\end{array}$ & $\begin{array}{c}\mathbf{T g ~ D S C}^{\text {a) }} \\
\left({ }^{\circ} \mathbf{C}\right)\end{array}$ & $\begin{array}{c}\mathbf{T} \boldsymbol{\alpha}^{\mathrm{b})} \\
\left({ }^{\circ} \mathbf{C}\right)\end{array}$ & $\begin{array}{c}\mathbf{M}_{\mathbf{n}}{ }^{\mathbf{c})} \\
(\mathbf{g} / \mathbf{m o l})\end{array}$ & $\mathbf{I}_{\mathbf{p}}{ }^{\mathbf{c})}$ \\
\hline A & 75 & 43 & 41 & 10500 & 2.3 \\
B & 90 & 48 & 45 & 20000 & 2.5 \\
C & 100 & 46 & 43 & 16500 & 1.9 \\
D & 120 & 41 & 38 & 8000 & 2 \\
\hline
\end{tabular}
a) $: \pm 2^{\circ} \mathrm{C}$
b) $: \pm 1{ }^{\circ} \mathrm{C}$
${ }^{\text {c) }}$ : Determined by SEC (RI detector, DMF-eq PMMA). 